\title{
The lipid profile in patients with subclinical Hypothyroidism and Metabolic Syndrome
}

Vesna Popović-Radinović, Zorica Rašić-Milutinović, Jelena Tica-Jevtić, Marina Vujović, Zoran Gluvić and Milena Lačković KBC Zemun, Endocrinology

\section{INTRODUCTION}

The lipid profile is disturbed in both subclinical hypothyroidism (SH) and metabolic syndrome (MetS).

AIM
The aim of this study was to try to find changes of lipid profile in
patients who developed subclinical hypothyroidism and
metabolic syndrome

\section{MATHERIAL AND METHODS}

We chose 70 patients (all females) with newly discovered SH and 20 healthy controls, mean age 51.1 ( \pm 6.79 ). The parameters that we determined are: TSH, FT4, AntiTPO-At, triglycerides, whole, LDL and HDL cholesterol. For statistical calculations we used EXCEL, Med-Calc and SPSS Programs.

\section{RESULTS}

The patients were additionally divided in 2 subgroups, considering existence of D.mell.type2 (DM), 1 with and the other without DM.The patients had higher levels of whole and LDL cholesterol than the control group ( $p=0.02)$. The levels of triglycerides had no difference between groups. The percentage of women with level of HDL cholesterol lower than 1.29 $\mathrm{mmol} / \mathrm{L}$ is almost the same in the 3 groups $(p=0.953)$. The percentage of women with level of triglycerides higher than 1.69 $\mathrm{mmol} / \mathrm{L}$ is statistically significant between 3 groups $(p=0.01)$. We didn't find correlation between TSH, FT4 and antiTPOAt and levels of triglycerides and cholesterol.

\section{Concentration of $\mathrm{Tg} \quad \geq 1,69 \mathrm{mmol} / \mathrm{L}$}

80

70

60

50

$0^{40}$

30

20

10

0

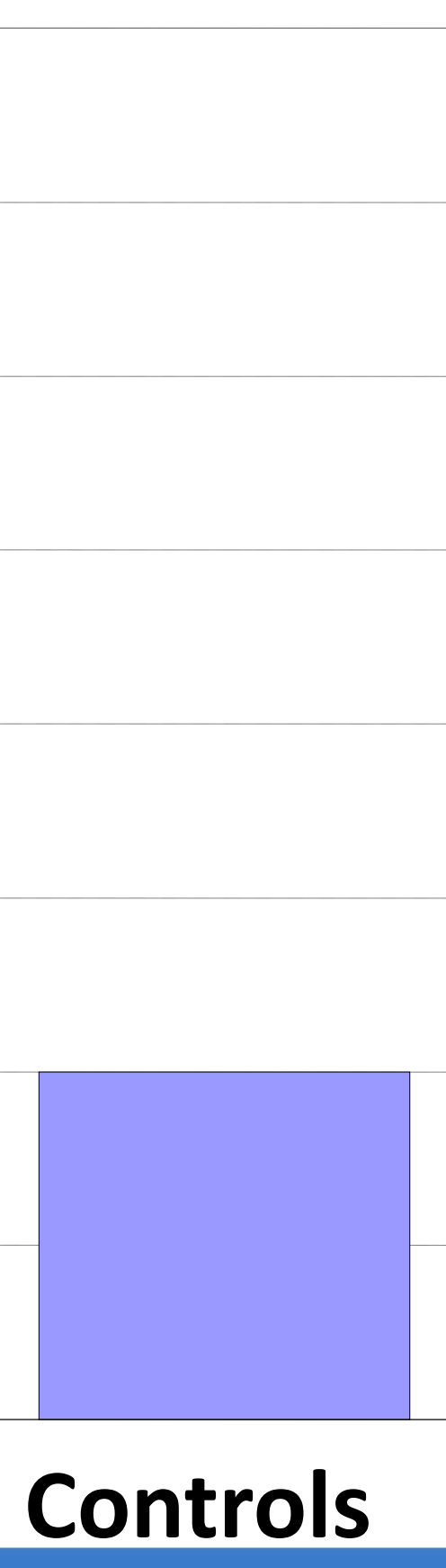

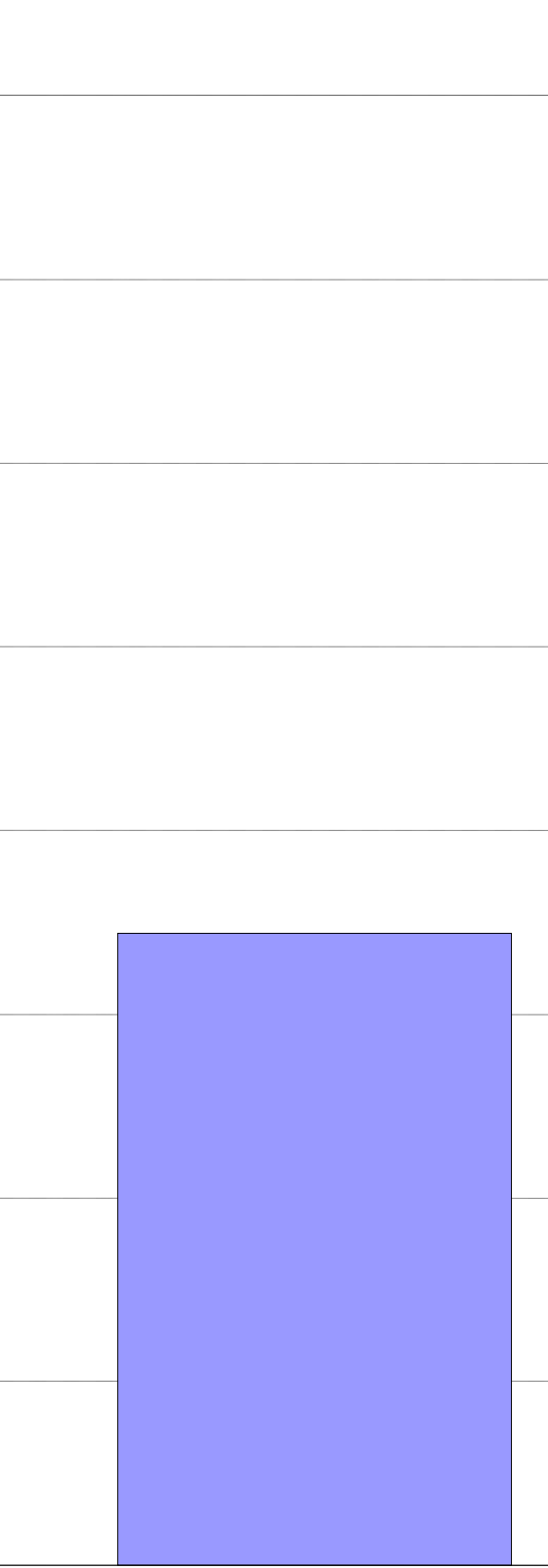

SHypo without DM

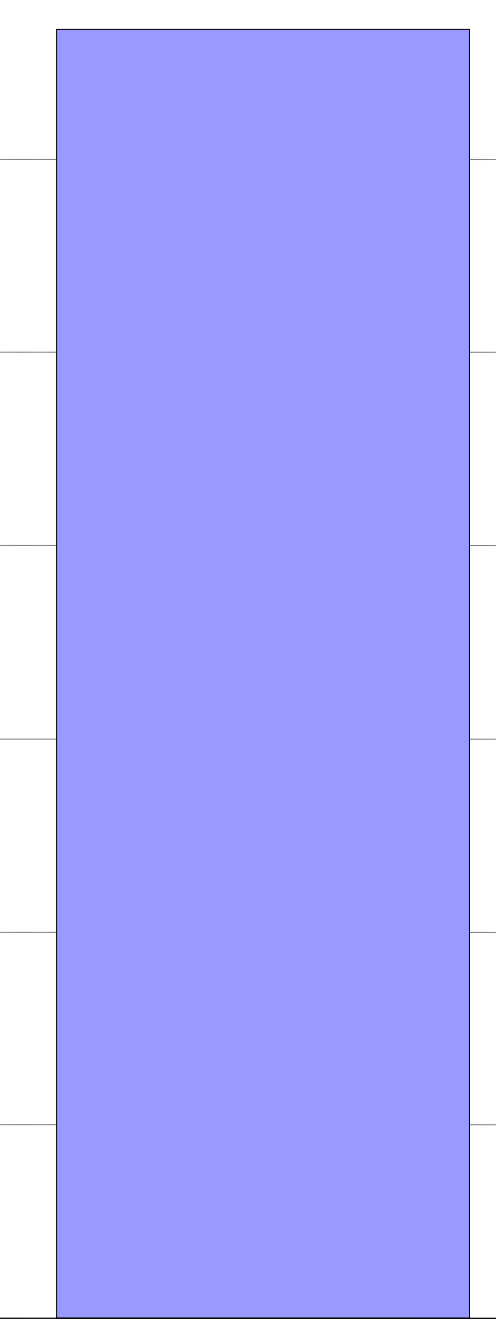

SHypo with DMT2

Percentage of patients with concentration of $\mathrm{Tg}>1.69$ $\mathrm{mmol} / \mathrm{L}$ is significantly different between three groups $(p=0.010)$. The greatest percentage of patients with high $\mathrm{Tg}$ is in the group with subclinical hypothyroidism and Diabetes mellitus typ2 $(66,7 \%)$, and the lowest is in the control group (20\%).

\begin{tabular}{|c|c|c|c|}
\hline Components of MetS & Controls & SH without DMT2 & SH with DMT2 \\
\hline Waist $\geq 80 \mathrm{~cm}$ & $50 \%$ & $93,4 \%$ & $93,4 \%$ \\
\hline HDLcholesterol $\leq 1,26 \mathrm{mmol} / \mathrm{I}$ & $40 \%$ & $43,3 \%$, & $44,3 \%$ \\
\hline Triglicerids $\geq 1,69 \mathrm{mmol} / \mathrm{l}$ & $20 \%$ & $34 \%$ & $66,7 \%$ \\
\hline Glicaemia $\geq 5,6 \mathrm{mmol} / \mathrm{l}$ & $20 \%$ & $34,4 \%$ & $94,4 \%$ \\
\hline $\mathrm{TA} \geq 130 / 85 \mathrm{mmHg}$ & $20 \%$ & $52 \%$ & $78.9 \%$ \\
\hline
\end{tabular}

\section{CONCLUSION}

Considering the results of this study we may conclude that the patients with SH and MetS may have a higher risk for developing coronary disease and/or hypertension 